\title{
Delineando o Perfil Feminino Discente do Bacharelado em Ciência da Computação do IFCE campus Aracati
}

\author{
Rhayane da S. Monteiro ${ }^{1}$, Jarina M. P. Marinho ${ }^{1}$, Reinaldo B. Braga ${ }^{1}$, \\ Márcia de N. Viana ${ }^{1}$, Carina T. de Oliveira ${ }^{1}$ \\ ${ }^{1}$ Instituto Federal de Educação, Ciência e Tecnologia do Ceará - Campus Aracati \\ Aracati - CE- Brasil \\ rhayane97monteiro@gmail.com, \{mara.marinho, reinaldo.braga, \\ marcia.viana, carina.oliveira\}@ifce.edu.br
}

\begin{abstract}
The study of female performance in courses of Information and Communication Technology (ICT) is relevant to the market and the academy in the context of gender equality promotion. However, only few researchers outline the profile of female ICT students. These researchers are important to support the implementation of strategies to ensure the permanence and success of female students. In this paper, the profile of female students from the undergraduate course in Computer Science of the IFCE Campus Aracati is outlined. Among the results obtained, we highlight the discrepancy between the profile of students enrolled and evaded. Also, the results were used to the development of actions to encourage the permanence and success of students.
\end{abstract}

Resumo. O estudo da atuação feminina nos cursos da área de Tecnologia da Informação e Comunicação (TIC) é relevante para o mercado e a academia no contexto da promoção da igualdade de gênero. Contudo, ainda são poucas as pesquisas que retratam o perfil das alunas da área de TIC. Tais pesquisas são importantes para suporte à implementação de estratégias de permanência e êxito das alunas. Neste trabalho, é delineado o perfil das alunas do curso de Bacharelado em Ciência da Computação do IFCE campus Aracati. Dentre os resultados obtidos, destaca-se a discrepância entre o perfil das alunas matriculadas e desistentes. Os resultados também auxiliaram no desenvolvimento de ações de incentivo à permanência e êxito das alunas.

\section{Introdução}

A conquista da igualdade de gênero está diretamente atrelada ao empoderamento da mulher, que, por sua vez, caminha ao lado da educação formal e consequente profissionalização [ONU Mulheres 2017]. Para tanto, deve-se investir fortemente na adesão feminina em todos os campos do saber, sendo maior o desafio da inclusão na área de Tecnologia da Informação e Comunicação (TIC), desmistificando o tradicional pensamento que costuma associar as áreas de exatas a uma suposta "vocação masculina".

A temática de empoderamento de mulheres na área de TIC vem sendo cada vez mais estudada e discutida, tanto no ambiente acadêmico quanto no mercado profissional. Conforme o National Center for Women \& Information Technology (NCWIT), no ano de 2015 as mulheres representavam apenas 25\% das ocupações relacionadas à Ciência da Computação [NCWIT 2016]. No cenário brasileiro, dados do Instituto Nacional de Estudos e Pesquisas Educacionais (INEP) revelam que o 
percentual de ingressos e concluintes do gênero feminino na área de "Ciências, Matemática e Computação" é inferior à masculina em todas as regiões do país [INEP 2014]. A gravidade de tal disparidade produz reflexos na inclusão profissional, tendo em vista que o mercado de trabalho tem sido cada vez mais receptivo a egressos de cursos de TIC, e oferece empregos mais interessantes, maiores salários, e maiores possibilidades de progressão em relação a outras carreiras.

Existem diversos projetos para incentivar o ingresso de mulheres nos cursos de TIC. Contudo, observa-se que há poucos estudos para delinear o perfil das alunas desses cursos [Figueiredo et al. 2016]. Esses estudos são importantes por fornecerem meios para a implementação de estratégias de permanência e êxito das alunas. Como passo nessa direção, Figueiredo et al. [2016] realizaram um estudo quantitativo para conhecer o número de mulheres ingressantes por semestre, as formas de ingresso delas e sua situação atual. Entretanto, ainda são necessárias discussões e análises mais aprofundadas para traçar o perfil feminino das estudantes matriculadas.

Visando aprofundar o conhecimento sobre o perfil feminino discente na área de TIC, o objetivo deste artigo é delinear o perfil das alunas do curso de Bacharelado em Ciência da Computação do Instituto Federal de Educação, Ciência e Tecnologia do Ceará (IFCE) campus Aracati. É fundamental conhecer esse perfil para que seja realizado o desenvolvimento adequado de ações de incentivo à permanência e êxito das alunas do curso e, além disso, identificar mecanismos que possam contribuir para o aumento do número de mulheres ingressantes na área de TIC.

\section{Contexto do curso de Bacharelado em Ciência da Computação}

O curso de Bacharelado em Ciência da Computação (BCC) do IFCE campus Aracati teve seu início no ano de 2012. As formas de ingresso são: via processo seletivo público pelo Sistema de Seleção Unificado (SiSU), como aluno especial, graduado ou transferido. O curso tem duração de 4 anos e sua oferta é semestral, com turnos vespertino e noturno intercalados a cada semestre.

\section{Resultados}

O percurso metodológico para a coleta de dados, visando conhecer o perfil das alunas de BCC do IFCE campus Aracati, constituiu-se em realizar análises de dados de 62 estudantes entre os semestres 2012.1 e 2016.2. Esse número corresponde ao total de alunas que já ingressou no curso. Os indicadores escolhidos para realizar a análise do perfil feminino discente do curso foram: a situação da matrícula, a faixa etária, a procedência escolar e a renda familiar. Estes indicadores fazem parte do banco de dados do Sistema Acadêmico do IFCE para acompanhamento dos alunos. O levantamento e análise dos indicadores ocorreram no período de janeiro a fevereiro de 2017.

\subsection{Situação da Matrícula}

Ao fazermos uma análise da situação da matrícula, referente ao Gráfico 1(a), constatamos que a taxa de matriculados entre homens e mulheres por ano, desde 2012, vem sendo predominantemente de gênero masculino. Este dado enfatiza a disparidade da quantidade de matrículas por sexo. Contudo, esse resultado não surpreende porque acompanha a tendência de pesquisas já realizadas em âmbito nacional e internacional, que mostram que o número de homens matriculados ainda é superior ao de mulheres em cursos da área de TIC. Os dados obtidos pelo Sistema Acadêmico do IFCE apontam que 
a taxa de mulheres matriculadas é de $23 \%$.
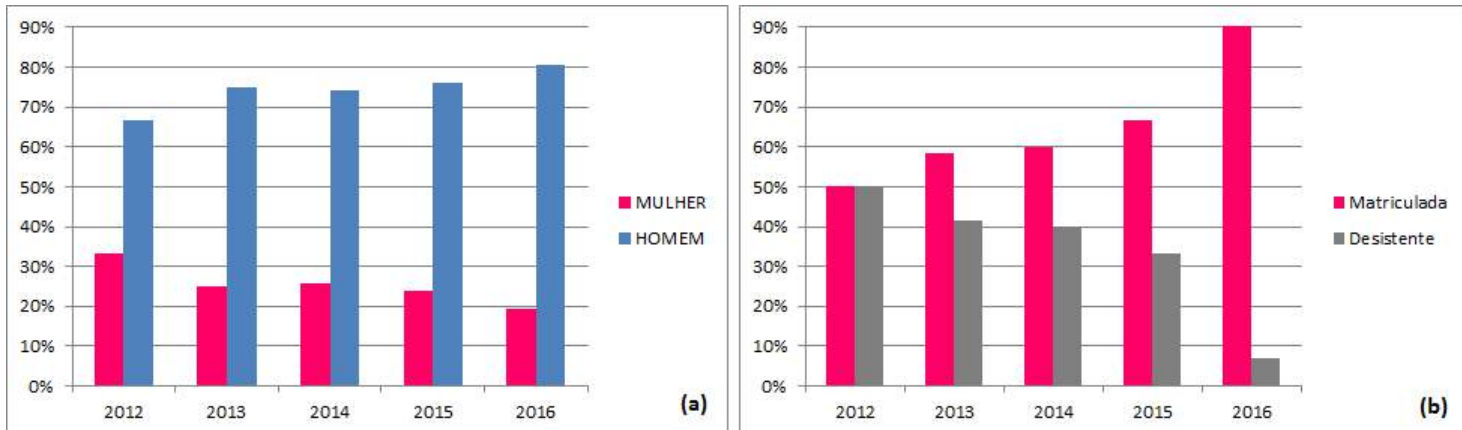

Gráfico 1. (a) Matriculados por Ano, (b) Situação das alunas por Ano.

O Gráfico 1(b) representa a situação da taxa de alunas matriculadas e a taxa de desistentes do curso em função do ano. Considerando a desistência, esta representa as estudantes que evadiram, abandonaram ou cancelaram sua matrícula. O Gráfico 1(b) aponta que a taxa de alunas matriculadas cresceu paulatinamente a cada ano, tendo uma maior participação de discentes matriculadas entre os anos de 2015 a 2016. Esse resultado é bastante animador porque mostra que mais alunas estão permanecendo no curso.

\subsection{Faixa Etária}

Ao tratarmos da faixa etária das alunas, o Gráfico 2 apresenta que a maioria das alunas matriculadas está na faixa etária entre 18 e 23 anos, representando assim, um público jovem. O menor índice de estudantes matriculadas é entre 30 e 40 anos de idade, representando cerca de $10 \%$. Também nesta faixa etária registrou-se o maior número de desistentes. As alunas de 18 a 23 anos foram as que apresentaram menor índice de desistência, girando em torno de $5 \%$.

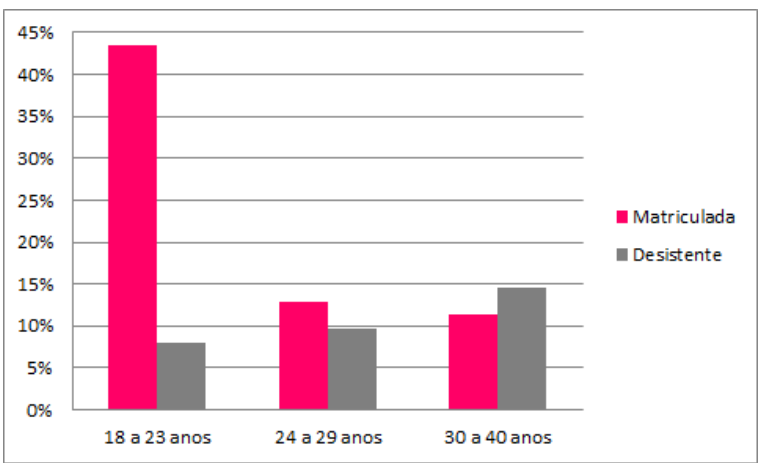

Gráfico 2. Situação das alunas por faixa etária.

\subsection{Procedência Escolar}

A análise da procedência escolar tem como objetivo entender a influência da escola de origem na permanência do curso. O Gráfico 3 aponta que a maior parte de estudantes matriculadas é proveniente de escola pública e pouco mais de $20 \%$ é de escola privada Em relação as alunas desistentes, aproximadamente $25 \%$ delas são de escola pública e apenas $4 \%$ das estudantes que desistiram do BCC estudaram em escola privada. Apenas $6 \%$ das alunas não informaram a procedência escolar. 


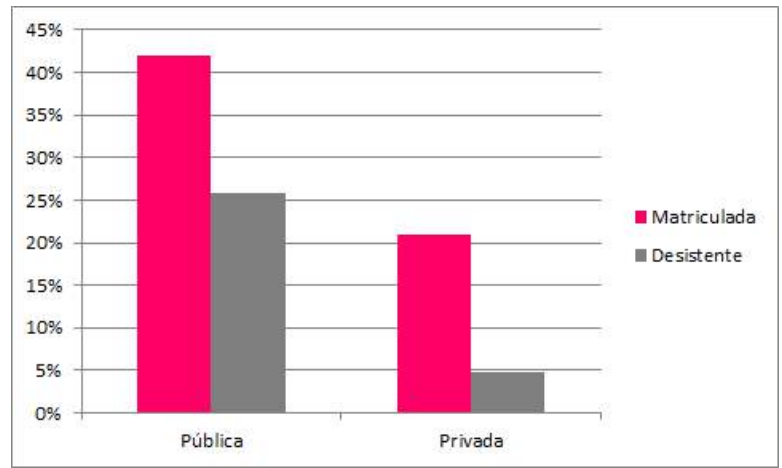

Gráfico 3. Situação das alunas por procedência escolar.

\subsection{Renda Familiar}

A renda familiar é um indicador relevante porque permite identificar o grau de influência que este gera para a permanência ou não das alunas no BCC. Dessa forma, o Gráfico 4 mostra que a maior parte das estudantes matriculadas tem renda familiar entre um a dois salários mínimos. Considerando as desistentes, a maioria delas tem renda de até um salário mínimo. As menores taxas foram registradas na faixa salarial superior a 3 salários. Aproximadamente $3 \%$ do total de alunas não informaram a renda familiar.

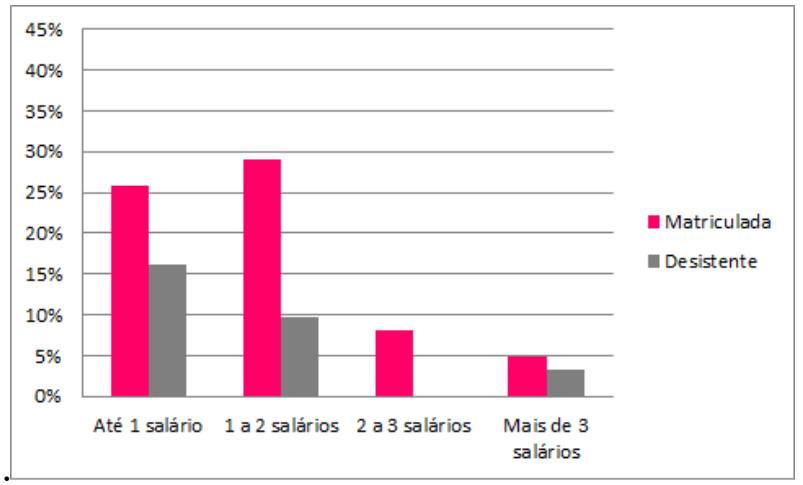

Gráfico 4. Situação das alunas por renda familiar.

\section{Conclusões e Trabalhos Futuros}

Este artigo teve como objetivo delinear o perfil das alunas do curso de Bacharelado em Ciência da Computação do IFCE campus Aracati. Entre os resultados alcançados com esse estudo temos que: o número de alunas que permanece matriculada aumentou ao longo dos anos no curso. Contudo, o número de desistentes ainda é elevado. Além disso, o maior número de estudantes matriculadas está na faixa etária de 18 a 23 anos e a maior parte das alunas é oriunda de escola pública. Por fim, constatamos que a maioria das alunas regularmente matriculadas apresenta renda familiar entre um e dois salários mínimos.

Os resultados levantados nessa pesquisa vêm sendo utilizados para o desenvolvimento de ações de incentivo à permanência e êxito das alunas. Como exemplos, citamos reuniões de acompanhamento e nivelamento das alunas, além de aulas preparatórias para maratonas de programação locais e nacionais. Também destacamos a criação de projetos de pesquisa e extensão com foco na permanência e 
êxito das estudantes, como o projeto intitulado DesenvolvImento de ações socioeducatiVas para inclusão, desmistificAção e empoderamento da mulher em tecnologiaS da informação e comunicação (DIVAS) [DIVAS 2017]. O projeto DIVAS é parceiro do programa nacional Meninas Digitais da Sociedade Brasileira de Computação (SBC) [Meninas Digitais 2017]. Uma das atividades do DIVAS foi a realização de diversas ações em escolas públicas por alunos e alunas do curso para incentivar a entrada de meninas do ensino fundamental e médio nos cursos de Técnico em Informática e Bacharelado em Ciência da Computação do IFCE campus Aracati. Além disso, os resultados da presente pesquisa foram apresentados para a direção, coordenação técnico-pedagógica e coordenação de assistência estudantil da instituição com o objetivo de buscar soluções para amenizar problemas associados à renda familiar para que esse indicador não cause problemas de evasão escolar.

Como trabalhos futuros, espera-se realizar um comparativo com o perfil masculino do curso. Além disso, espera-se comparar os dados do Sistema Acadêmico de outros cursos de TIC da instituição. Por fim, acreditamos que as características do município (ex: Produto Interno Bruto - PIB, Índice de Desenvolvimento Humano - IDH, etc) onde o curso é ofertado também repercutem no acesso, permanência e êxito dos alunos e em especial, as do gênero feminino.

\section{Agradecimentos}

Este trabalho é um resultado parcial do projeto DIVAS (DesenvolvImento de ações socioeducatiVas para inclusão, desmistificAção e empoderamento da mulher em tecnologiaS da informação e comunicação), financiado pelo edital PAPEX/IFCE/2016.

\section{Referências}

DIVAS. Projeto DesenvolvImento de ações socioeducatiVas para inclusão, desmistificAção e empoderamento da mulher em tecnologiaS da informação e comunicação do IFCE campus Aracati. Disponível em $<$ http://ifce.edu.br/aracati/menu/projetos-de-extensao/divas $>$. Último acesso em 03Maio-2017.

Figueiredo, R. et al. (2016) Um Estudo Inicial Sobre As Alunas Ingressantes no Curso de Licenciatura em Ciência da Computação da Universidade Federal da Paraíba. In: Congresso da Sociedade Brasileira de Computação (CSBC). Porto Alegre: SBC.

INEP. Censo da Educação Superior 2012: Resumo Técnico (2014). Instituto Nacional de Estudos e Pesquisas Educacionais Anísio Teixeira.

Meninas Digitais (2017). Programa Meninas Digitais da Sociedade Brasileira de Computação. Disponível em <http://meninasdigitais.sbc.org.br/>. Último acesso em 02-Maio-2017.

NCWIT (2016). Relatório Women in Tech: The Facts. Disponível em $<$ http.//https://www.ncwit.org/sites/default/files/resources/ncwit_women-in-it_2016full-report_final-web06012016.pdf>.

ONU Mulheres. Entidade das Nações Unidas para a Igualdade de Gênero e o Empoderamento das Mulheres. Disponível em <http://www.onumulheres.org.br/>. Último acesso em 24-Março-2017. 